\title{
Connectedness to Nature is More Strongly Related to Connection to Distant, Rather Than Close, Others
}

\author{
Sam Moreton, Andrew Arena, and Nikolaos Tiliopoulos \\ School of Psychology, University of Sydney, Camperdown, \\ Australia.
}

\section{Abstract}

Much research supports the contention that human beings have a fundamental need to belong (Baumeister \& Leary, 1995). This need can be satisfied by social connections such as friends and family or by a connection to more abstract entities such as culture, country, or humanity as a whole (McFarland, Webb, \& Brown, 2012). Ecopsychologists have also argued that the need to belong can be satisfied by feeling connected to nature (Baxter \& Pelletier, 2018; Mayer, Frantz, Bruehlman-Senecal, \&t Dolliver, 2009; Passmore \&t Howell, 2014). Despite conceptual similarities between connectedness to nature and social connectedness (Schultz, 2002), there have been conflicting findings in the literature regarding relations between these two constructs. The aim of the present study was to help clarify the relationship between social connectedness and connectedness to nature by measuring multiple forms of both of these broad constructs. Key Words: Connectedness to nature-Social connectedness-Belonging-Need to belong.

\section{Connectedness to Nature}

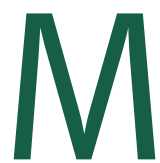
any scholars have argued that, similar to how humans form feelings of connection with other humans, positive experiences with nature can lead to an emotional affinity and cognitive identification with nature (Kals, Schumacher, \& Montada, 1999; Leopold, 1949; Mayer et al., 2009; Wilson, 1984). A range of constructs have been introduced in the literature which all represent related components of a connection with nature (see Tam, 2013). While these constructs differ in specific focus, they all describe some form of relationship toward an abstract, generalized "nature" (Beery \&t Wolf-Watz, 2014). Tam (2013) found that scales targeting these constructs tended to converge around a common factor, implying they are all tapping into the same construct, which we will refer to as connectedness to nature.

However, supporting the proposition that connectedness to nature can be split into distinct affective and cognitive components (Schultz, 2002), Tam (2013) found divergence between measures of emotional and cognitive connectedness to nature. While measures of emotional connection-for example the Connectedness to Nature Scale (Mayer \& Frantz, 2004) and the Love and Care for Nature Scale (Perkins, 2010)-assess an affective bond with nature, measures of cognitive connectedness to nature-such as the Inclusion of Nature in Self Scale (Schultz, 2002) and the Allo-Inclusive Identity Nature subscale (Leary, Tipsord, \& Tate, 2008)-assess the degree to which nature is included in one's schema of the self.

\section{The relationship between social connectedness and connectedness to nature}

The case for a negative relationship. Although connectedness to nature and social connectedness are conceptually similar-and both have been argued to be able to satisfy the need to belong (Cleary, Fielding, Bell, Murray, \&t Roiko, 2017; Mayer et al., 2009; Passmore \& Howell, 2014)-only a small amount of research has focused specifically on their relationship. Prima facie, there are reasons to expect that social and nature connection could be negatively related. For instance, the rise of "nature religions" has arguably been driven by increased alienation from society, as people seek connection that they cannot find in society (Kramp, 2013). Conversely, people whose relatedness needs are satisfied by other humans may not be motivated to seek a connection with 


\section{MORETON ET AL.}

nonhuman entities. Similarly, people who feel a deep sense of connection with nature (e.g., hermits, naturalists) may not feel the need to foster social connectedness.

Baumeister and Leary (1995) argue that the need to belong operates as a drive state. Like seeking food when hungry, people will seek out reconnection with other human beings when they feel socially disconnected (Maner, DeWall, Baumeister, \& Schaller, 2007). Decreased social connectedness has also been shown to increase motivations to connect to nonhuman entities. For example, Epley, Waytz, Akalis, and Cacioppo (2008) found that both trait and state loneliness predicted increased anthropomorphism of nonhuman agents and a belief in God, which the authors argue occurs to facilitate connection. Since nature as a whole has been proposed as a source of belonging, people may seek out a connection with nature in order to cope with a lack of social connectedness. Along these lines, Poon, Teng, Chow, and Chen (2015) found that ostracism increased desires to connect to nature. It is plausible that given time, the desire to connect to nature could translate into the development of increased feelings of connectedness to nature. Thus, decreased feelings of social connectedness could lead to the development of connectedness to nature.

Additionally, there is complementary evidence that higher levels of social connectedness may lead to an emotional distancing from the natural world. Waytz and Epley (2012) argue that close relationships (i.e., friends and family) diminish the motivation to affiliate with distant others. Specifically, they found that the satisfaction of relatedness needs (such as by bringing a friend to the experiment) led to increased dehumanization of out-groups. In a similar fashion, individuals higher in social connectedness may also be less motivated to form connections with nature.

The case for a positive relationship. However, there are conceptual similarities between social connectedness and connectedness to nature which imply the possibility of a positive relationship. For instance, both involve commitment (Davis, Green, \&t Reed, 2009) and inclusion of the other (nature or other person) in the self-concept (Aron, Aron, Tudor, \& Nelson, 1991; Schultz, 2002). These similarities imply that social connectedness and connectedness to nature may positively correlate due to shared personality variables that govern the tendency to feel a sense of attachment. It may be that certain types of people are "connection" prone and, thus, are more likely to feel a sense of connection both to other people and to the natural world.

Supporting this hypothesis that social and nature connection may be positively related, a number of studies have found significant positive relations between measures of social connectedness and connectedness to nature. Trigwell, Francis, and Bagot (2014) reported a significant correlation $(r=.26)$ between the Connectedness to Nature Scale and the Positive Relations with Others subscale of the Scales of Psychological Well-Being (Ryff \& Keyes, 1995): a measure of the extent to which an individual has warm, trusting, intimate relationships with others. Similarly, Howell, Dopko, Passmore, and Buro (2011) found positive correlations between "social well-being" (i.e., feelings of social acceptance and integration) and the Connectedness to Nature Scale (Study 1, $r=.20$; Study 2, $r=.23$ ), the Nature Relatedness Scale ( $r=.29$, Study 2), and the Allo-Inclusive Identity Nature subscale ( $r=.21$, Study 2). Howell, Passmore, and Buro (2013) found comparable correlations between social wellbeing and the Connectedness to Nature Scale (Study 1, $r=.26$; Study 2, $r=.19$ ), the Nature Relatedness Scale (Study 1, $r=.21$ ), and the Allo-Inclusive Identity Nature subscale (Study $1, r=.17$ ). Lee, Ashton, Choi, and Zachariassen (2015) found correlations between the Connectedness to Nature Scale with feelings of connection to humanity in general $(r=.44)$, identification with country $(r=.32)$, and identification with community $(r=.26)$. Furthermore, Leary et al. (2008) found that the Nature and Humanity subscales of the Allo-Inclusive Identity Scale moderately correlated $(r=.35)$. In reviewing the literature, Passmore and Howell (2014) conclude that "in multiple studies utilizing multiple measures, social well-being has been show [sic] to correlate significantly with nature affiliation" (p. 378). Passmore and Howell (2014) also suggest a causal mechanism underlying this relation: "experiences with nature afford us a greater sense of relatedness and social connectedness" (emphasis added, p. 377).

However, a number of studies have reported negligible correlations between several forms of social connectedness and connectedness to nature. Unlike the findings of Trigwell et al. (2014), who utilized the Connectedness to Nature Scale, Nisbet, Zelenski, and Murphy (2011) found nonsignificant zero-order correlations across two studies ( $r=.10$ and .07 ) between the 21-item Nature Relatedness Scale and the Positive Relations with Others subscale of Ryff and Keyes' (1995) Scales of Psychological Well-Being (Ryff \& Keyes, 1995). Likewise, Zelenski and Nisbet (2014) reported largely nonsignificant correlations between the same 21-item Nature Relatedness Scale and measures of loneliness, belonging, attachment, interdependence, and collective identity. They remark that "somewhat surprisingly, nature relatedness appears largely distinct from these other connections" (p. 15).

Aims

Thus far we have reviewed conflicting theoretical evidence for a relationship between social connectedness and connectedness to 


\section{SOCIAL CONNECTEDNESS AND CONNECTEDNESS TO NATURE}

nature and documented the inconsistent findings in the literature pertaining to this relationship. The previous research has been inconclusive, in part, because each study has used different measures of both social and nature connectedness. The goal of the present study was to develop a clearer understanding of the relationship between social and nature connectedness by testing correlations between multiple indices of each. As part of this approach, we incorporated measures of both cognitive and emotional dimensions of connectedness to nature. We also measured social connectedness in terms of concrete interpersonal ties with significant others, ties with hypothetical strangers, and abstract connections with social identities. By doing so, we aimed to provide an authoritative picture of the relationship between these two broad constructs, and to be able to identify possible boundary conditions around the relationship.

\section{Method}

\section{Participants and procedure}

A total of 286 first-year Australian psychology students (203 female, $M_{\text {age }}=20.16$ years, $S D=3.35$ ) completed an online survey in return for course credit. After giving informed consent, participants completed the measures in a randomized order.

\section{Measures of connectedness to nature}

The Connectedness to Nature Scale (CNS; Mayer \& Frantz, 2004) is a 14-item measure of an individual's trait levels of emotional connectedness to nature that is scored on a 5-point Likert scale. An example item is "I feel a sense of oneness with the natural world around me." High internal consistency $(\alpha>.80)$ has been reported (Mayer Et Frantz, 2004). Although there has been some contention that the scale may be measuring cognitive connectedness to nature (Perrin \& Benassi, 2009), Tam (2013) found that the Connectedness to Nature Scale converged with measures of emotional connectedness to nature, supporting its original conceptualization.

The Inclusion of Nature in Self Scale (INS; Schultz, 2002) is a measure of cognitive connectedness to nature that measures people's inclusion of nature within their self-concept. It is a single item whereby participants select one of seven pairs of circles that represent varying degrees of overlap between nature and self.

The Nature subscale of the Allo-Inclusive Identity Scale (AII-NS; Leary et al., 2008) measures people's perceptions of shared identity with different elements of nature. Participants choose one of seven diagrams depicting an incremental overlap between a circle labeled "you" and another labeled "Other." For instance, a participant would select the circle that best represented "The connection between you and an eagle soaring in the sky." The scale possesses acceptable re- liability, with Leary et al. (2008) finding an alpha above .75. Although not originally conceptualized as a measure of connectedness to nature, the content of the scale and criterion relationships support its classification as a measure of cognitive connectedness to nature (Tam, 2013).

\section{Measures of social connectedness}

The Social Connectedness Scale (Lee \& Robbins, 1995) is an 8-item measure of interpersonal social connectedness with other people in one's life. An example item is "Even around people I know, I don't feel like I belong." It is rated on a 5-point Likert scale. This scale has reported excellent internal consistency $(\alpha=.91)$ and has been used in a large number of experimental and clinical studies. As wording in the scale is reversed, we refer to the measured construct as social disconnection.

The UCLA Loneliness Scale (Russell, 1996) is a 20-item measure of feelings of interpersonal loneliness. It is scored on a 4-point scale from Never to Often. An example item is "There are people I feel close to" (R). The scale has reported excellent internal consistency, with Russell (1996) finding Cronbach's alphas between .89 and .94.

The Humanity subscale of the Allo-Inclusive Identity Scale (AIIHS; Leary et al., 2008) measures people's perceptions of shared identity with different individuals and groups of humans. It shares the methodology of the Allo-Inclusive Identity Nature subscale described above and consists of eight items measuring identity overlap with close others (e.g., "your best friend of the same sex") as well as distant others ("a homeless person on the street"). The scale possesses acceptable reliability, with Leary et al. (2008) finding a Cronbach's alpha above .75 .

The Identification with All Humanity Scale (McFarland et al., 2012) measures feelings of connectedness toward targets that are increasingly distant from the individual: community, country, and all humanity. It consists of nine three-part items, each asking about attitudes toward "(a) people in my community, (b) people in my country, (c) all humans everywhere." An example question is "How much would you say you care (feel upset, want to help) when bad things happen to..." from Not at all to Very much. The subscales possess good internal consistency, with McFarland et al. (2012) generally finding Cronbach's alphas between .75 and .90 .

\section{Results}

We conducted two sets of correlations. The first set of correlations examined all the indices of connectedness to nature with all the indices of social connectedness, with the exception of the AlloInclusive Humanity subscale (see Table 1). The second set of correlations examined all the indices of connectedness to nature with each 
MORETON ET AL.

\begin{tabular}{|c|c|c|c|c|c|c|c|c|c|}
\hline VARIABLES & $M(S D)$ & 1 & 2 & 3 & 4 & 5 & 6 & 7 & 8 \\
\hline 1. Connectedness to Nature & $3.31(.51)$ & $(.82)$ & & & & & & & \\
\hline 2. Inclusion of Nature in Self & $3.51(1.40)$ & $.62^{* * *}$ & & & & & & & \\
\hline 3. Allo-Inclusive Nature & $2.77(1.15)$ & $.58^{* * *}$ & $.71^{* * *}$ & (.89) & & & & & \\
\hline 4. Loneliness & $3.21(.48)$ & -.01 & $-.17^{* *}$ & -.08 & $(.92)$ & & & & \\
\hline 5. Social Disconnection & $2.22(.76)$ & -.06 & $-.20^{* *}$ & -.08 & $.81^{* * *}$ & (.92) & & & \\
\hline 6. Connection to Community & $3.56(.77)$ & $.18^{* *}$ & $.15^{* *}$ & .05 & $-.24^{* * *}$ & $-.27^{* * *}$ & (.90) & & \\
\hline 7. Connection to Australians & $3.45(.66)$ & $.18^{* *}$ & $.19^{* *}$ & $.14^{*}$ & $-.26^{* * *}$ & $-.28^{* * *}$ & $.58^{* * *}$ & (.86) & \\
\hline 8. Connection to Humanity & $3.25(.61)$ & $.35^{* * *}$ & $.31^{* * *}$ & $.35^{* * *}$ & $-.13^{*}$ & $-.16^{* *}$ & $.45^{* * *}$ & $.59^{* * *}$ & (.83) \\
\hline
\end{tabular}

Note. Cronbach's alpha internal consistency reliabilities are stated in the main diagonal.

${ }^{*} p<.05 .{ }^{* *} p<.01 .{ }^{* * *} p<.001$.

individual item within the Allo-Inclusive Humanity subscale (see Table 2). This analysis was conducted as some items of the AlloInclusive Humanity subscale measure connection to close others (e.g., family, the person you are closest to), while other items measure connection to distant others (e.g., a homeless person, a stranger on a bus). Thus, as they are tapping into conceptually distinct forms of social connectedness, it was deemed more informative to look at correlations at the item level for this measure.

Overall, the majority of the correlations suggested a positive correlation between social connectedness and connectedness to

\begin{tabular}{|c|c|c|c|c|c|c|c|c|c|c|c|c|c|}
\hline VARIABLES & $M(S D)$ & 1 & 2 & 3 & 4 & 5 & 6 & 7 & 8 & 9 & 10 & 11 & 12 \\
\hline 1. Connectedness to Nature & $3.31(.51)$ & (.82) & & & & & & & & & & & \\
\hline 3. Allo-Inclusive Nature & $2.77(1.15)$ & $.58^{* * *}$ & $.71^{* * *}$ & (.89) & & & & & & & & & \\
\hline 4. Person you feel closest to & $5.85(1.17)$ & .02 & $.20^{* *}$ & .09 & & & & & & & & & \\
\hline 6. Best Friend Same Sex & $5.33(1.25)$ & $.21^{* * *}$ & $.36^{* * *}$ & $.26^{* * *}$ & $.61^{* * *}$ & $.46^{* * *}$ & & & & & & & \\
\hline 7. Best Friend Other Sex & $4.70(1.52)$ & .11 & $.21^{* * *}$ & $.17^{* * *}$ & $.52^{* * *}$ & $.40^{* * *}$ & $.53^{* * *}$ & & & & & & \\
\hline 8. Average Australian & $3.10(1.09)$ & $.24^{* * *}$ & $.42^{* * *}$ & $.27^{* * *}$ & $.30^{* * *}$ & $.29^{* * *}$ & $.48^{* * *}$ & $.40^{* * *}$ & & & & & \\
\hline 9. Stranger on Bus & $2.26(1.10)$ & $.26^{* * *}$ & $.35^{* * *}$ & $.39^{* * *}$ & $.18^{* *}$ & $.14^{*}$ & $.31^{* * *}$ & $.28^{* * *}$ & $.53^{* * *}$ & & & & \\
\hline 12. Total score for All-HS & $4.12(.85)$ & $.30^{* * *}$ & $.48^{* * *}$ & $.42^{* * *}$ & $.69^{* * *}$ & $.61^{* * *}$ & $.76^{* * *}$ & $.73^{* * *}$ & $.71^{* * *}$ & $.59^{* * *}$ & $.68^{* * *}$ & $.59^{* * *}$ & $(.82)$ \\
\hline
\end{tabular}

Note. Cronbach's alpha internal consistency reliabilities are stated in the main diagonal.

${ }^{*} p<.05 .{ }^{* *} p<.01 .{ }^{* * *} p<.001$. 


\section{SOCIAL CONNECTEDNESS AND CONNECTEDNESS TO NATURE}

nature. However, this relationship seemed to be stronger when social connectedness was measured with reference to abstract social categories (e.g., connection to people within one's nation and to humanity generally). As the social ties became more concrete and specific, the relationship weakened. For connection to one's community, for example, the positive correlation was only significant on 2 of 3 indices of connectedness to nature. For measures of how lonely and disconnected people felt with others on an interpersonal level, the positive correlation was only significant on 1 of 3 indices of connectedness to nature. Overall, though, it should be noted that there was no evidence for a negative relationship between the two constructs.

As seen in Table 2, the pattern of correlation between measures of connectedness to nature and the individual items of the AII-HS reflected the pattern of correlations in Table 1 . In 19 of the 24 relationships tested, social connectedness significantly correlated with connectedness to nature. Again, however, the relationship was notably weaker when participants rated their connection with concrete examples of people in their life. When participants rated their connection with abstract exemplars of social categories, the relationships were significant in all 12 cases (average $r=.37$ ). In contrast, when participants rated their connection with specific loved ones, the relationship was only significant in 7 of 12 cases (average $r=.17$ ).

\section{Discussion}

The present study clarified the relationship between social connectedness and connectedness to nature by measuring relations between multiple forms of these constructs. The correlations between social connectedness and connectedness to nature ranged from nonsignificant to positive moderate correlations depending on the measures. However, there were no significant negative correlations between any forms of these constructs.

\section{Implications}

Passmore and Howell (2014) suggest that experiences with nature afford humans greater social well-being. The results of the present study provide mixed support for this proposition. In general, there were nonsignificant or small correlations between connectedness to nature and measures of loneliness, social disconnection, and connection to close others (e.g., family, best friends). Nevertheless, there were consistent moderate correlations between connectedness to nature, and connection to abstract social groups (e.g., connectedness to all humanity) and distant others (e.g., "a homeless person on the street").

Although these data are correlational, they lend support to a more limited proposition that connectedness to nature may afford greater feelings of social connectedness to other humans at a more distal level of the moral circle (Singer, 2011). Interestingly, mirroring the observed correlational evidence in the present study, Saroglou, Buxant, and Tilquin (2008) found that viewing beautiful nature increased feelings of connection to humanity as a whole, but not connection to close others. Thus, although they did not specifically measure connectedness to nature, their findings are aligned with the present correlational evidence. Nevertheless, both the correlational evidence presented here and the experimental findings of Saroglou et al. (2008) suggest that connectedness to nature may not be able to stave off feelings of loneliness and facilitate feelings of connection to close others.

It must be noted that the Inclusion of Nature in Self item tended to show stronger correlations with measures of social connectedness compared to the Connectedness to Nature Scale and the AlloInclusive Identity Nature subscale. This finding dovetails with that of Zelenski and Nisbet (2014), who found that the Inclusion of Nature in Self item-compared to the Nature Relatedness Scale-had a stronger correlation with a connectedness composite comprised of different forms of social connectedness. Zelenski and Nisbet (2014) suggest that this finding may have been due to common-method variance. However, in the present study, Inclusion of Nature in Self generally showed stronger correlations with measures of social connectedness regardless of measurement method. This suggests that cognitive connectedness to nature may be more strongly related to social connectedness. However, providing some evidence against this claim, the Allo-Inclusive Identity Nature subscale (another measure of cognitive connectedness to nature) performed more similarly in this regard to the Connectedness to Nature Scale. Thus, the relative relatedness of cognitive and emotional forms of connectedness to nature with social connectedness remains ambiguous.

\section{Future directions}

Despite the nonsignificant to small correlations between measures of connectedness to nature and interpersonal social connection, the results of the present study do not strictly rule out the possibility of a causal effect of connectedness to nature in reducing feelings of loneliness. As suggested earlier, there is evidence to suggest that connectedness to nature may be motivated by decreased social connection, with Poon et al. (2015) finding that ostracism was linked with increased desires to connect with nature. As such, it is possible that, over time, social disconnection may motivate the development of connectedness to nature, which then feeds back to reduce feelings of loneliness. However, cross-sectional data would not be able to measure this dynamic relationship; both effects may cancel each other out when taking a temporal snapshot of the relationship. While not specifically measuring social disconnection and connectedness 


\section{MORETON ET AL.}

to nature, Poon, Teng, Wong, and Chen (2016) found that exposure to nature could reduce the effects of ostracism on aggressive behavior, thus providing indirect support for the idea that connectedness to nature may reduce feelings of interpersonal social disconnection-or at least reduce its effects. Future research could investigate the relationship between loneliness and connectedness to nature using longitudinal methods to tease out possible dynamic relations. It is possible that a temporal analysis would reveal that the development of connectedness to nature may lead to decreased feelings of loneliness.

Another possibility to consider is that the correlations that were observed between connectedness to nature and social connectedness may be explained by shared individual differences variables. Lee et al. (2015) found that the personality domains of Honesty-Humility and Openness to Experience explained a significant proportion of the relationship between connectedness to nature and connectedness to all humanity. Lee et al. (2015) note that a significant proportion of the variance was left unexplained, and they speculated that this could be due to either connection to humanity or connectedness to nature having a positive causal influence on the other. Nevertheless, it could also be the case that related individual differences not measured by Lee et al. (2015) may account for the unexplained shared variance between connectedness to humanity and connectedness to nature. For instance, Crimston, Bain, Hornsey, and Bastian (2016) found that both connectedness to all humanity and connectedness to nature are related to moral expansiveness: the tendency to include more distant entities in one's moral circle. This finding is not surprising, as both constructs tap into connection to entities at a more distal level of the moral circle. Moral expansiveness provides a possible explanation for the findings of the present study: The strength of the observed correlations between connectedness to nature and social connectedness followed a general trend where the more expanded the form of social connectedness being measured (i.e., the more morally distant the individual or group), the more it correlated with connectedness to nature. Out of all the measures of social connectedness, connectedness to humanity as a whole had the strongest relationship with connectedness to nature. These data are consistent with an effect of moral expansiveness explaining a significant proportion of the shared variance between connectedness to nature and social connectedness to distant individuals and groups, although this hypothesis would require future research to be corroborated.

\section{Conclusion}

The aim of the present work was to test relationships between different forms of social connectedness and connectedness to nature, and in doing so, help clarify a literature that has reported inconsistent relationships between these constructs. We found that the relationship between measures of social connectedness and connectedness to nature varied from nonsignificant to moderate positive correlations, and, interestingly, this relationship appeared to depend on how "expanded" the form of social connectedness being measured was. Although correlational, the present findings are consistent with the notion that connectedness to nature may facilitate broad feelings of connectedness to humanity; it may be that a rediscovery of the wild may also lead to a renewed appreciation of the unity of humanity. In this sense, the mission of ecopsychology to reconnect people with nature need not come at the expense of feelings of community with humanity, but, rather, may actually facilitate social harmony. We hope future research will expand on the present findings by testing the underlying causal mechanisms involved.

\section{Author Disclosure Statement}

The authors confirm that there are no known conflicts of interest associated with this publication and there has been no significant financial support for this work that could have influenced its outcome.

\section{REFERENCES}

Aron, A., Aron, E. N., Tudor, M., \& Nelson, G. (1991). Close relationships as including other in the self. Journal of Personality and Social Psychology, 60, 241-253.

Baumeister, R. F., \&t Leary, M. R. (1995). The need to belong: Desire for interpersonal attachments as a fundamental human motivation. Psychological Bulletin, 117, 497-529.

Baxter, D. E., \& Pelletier, L. (2018). Is nature relatedness a basic human psychological need? A critical examination of the extant literature. Canadian Psychology/ Psychologie canadienne. Advance online publication. doi:10.1037/cap0000145

Beery, T. H., \& Wolf-Watz, D. (2014). Nature to place: Rethinking the environmental connectedness perspective. Journal of Environmental Psychology, 40, 198-205.

Cleary, A., Fielding, K. S., Bell, S. L., Murray, Z., \& Roiko, A. (2017). Exploring potential mechanisms involved in the relationship between eudaimonic wellbeing and nature connection. Landscape and Urban Planning, 158, 119-128.

Crimston, D., Bain, P. G., Hornsey, M. J., \& Bastian, B. (2016). Moral expansiveness: Examining variability in the extension of the moral world. Journal of Personality and Social Psychology, 111, 636-653.

Davis, J. L., Green, J. D., \& Reed, A. (2009). Interdependence with the environment: Commitment, interconnectedness, and environmental behavior. Journal of Environmental Psychology, 29, 173-180.

Epley, N., Waytz, A., Akalis, S., \& Cacioppo, J. T. (2008). When we need a human: Motivational determinants of anthropomorphism. Social Cognition, 26, 143-155.

Howell, A. J., Dopko, R. L., Passmore, H.-A., \& Buro, K. (2011). Nature connectedness: Associations with well-being and mindfulness. Personality and Individual Differences, 51, 166-171.

Howell, A. J., Passmore, H.-A., \& Buro, K. (2013). Meaning in nature: Meaning in life as a mediator of the relationship between nature connectedness and wellbeing. Journal of Happiness Studies, 14, 1681-1696.

Kals, E., Schumacher, D., \& Montada, L. (1999). Emotional affinity toward nature as a motivational basis to protect nature. Environment and Behavior, 31, 178-202. 


\section{SOCIAL CONNECTEDNESS AND CONNECTEDNESS TO NATURE}

Kramp, J. M. (2013). Call of the wild: The negative tendency in the nature religions of American youth. Journal of Religion and Health, 54, 61-75.

Leary, M. R., Tipsord, J. M., \&t Tate, E. B. (2008). Allo-inclusive identity: Incorporating the social and natural worlds into one's sense of self. In H. A. Wayment \& J. J. Bauer (Eds.), Transcending self-interest: Psychological explorations of the quiet ego (pp. 137-147). Washington, DC: American Psychological Association.

Lee, K., Ashton, M. C., Choi, J., \&t Zachariassen, K. (2015). Connectedness to nature and to humanity: Their association and personality correlates. Frontiers in Psychology, 6, doi:10.3389/fpsyg.2015.01003

Lee, R. M., \& Robbins, S. B. (1995). Measuring belongingness: The Social Connectedness and the Social Assurance scales. Journal of Counseling Psychology, 42, 232241.

Leopold, A. (1949). Thinking like a mountain. In A sand county almanac (pp. 129132). New York, NY: Oxford University Press.

Maner, J. K., DeWall, C. N., Baumeister, R. F., \& Schaller, M. (2007). Does social exclusion motivate interpersonal reconnection? Resolving the "porcupine problem." Journal of Personality and Social Psychology, 92, 42-55.

Mayer, F. S., \& Frantz, C. M. (2004). The Connectedness to Nature Scale: A measure of individuals' feeling in community with nature. Journal of Environmental Psychology, 24, 503-515.

Mayer, F. S., Frantz, C. M., Bruehlman-Senecal, E., \& Dolliver, K. (2009). Why is nature beneficial? The role of connectedness to nature. Environment and Behavior, 41, 607-643.

McFarland, S., Webb, M., \& Brown, D. (2012). All humanity is my ingroup: A measure and studies of identification with all humanity. Journal of Personality and Social Psychology, 103, 830-853.

Nisbet, E. K., Zelenski, J. M., \&t Murphy, S. A. (2011). Happiness is in our nature: Exploring nature relatedness as a contributor to subjective well-being. Journal of Happiness Studies, 12, 303-322.

Passmore, H.-A., \&t Howell, A. J. (2014). Eco-existential positive psychology: Experiences in nature, existential anxieties, and well-being. The Humanistic Psychologist, 42, 370-388.

Perkins, H. E. (2010). Measuring love and care for nature. Journal of Environmental Psychology, 30, 455-463.

Perrin, J. L., \& Benassi, V. A. (2009). The Connectedness to Nature Scale: A measure of emotional connection to nature? Journal of Environmental Psychology, 29, $434-440$.

Poon, K.-T., Teng, F., Chow, J. T., \& Chen, Z. (2015). Desiring to connect to nature: The effect of ostracism on ecological behavior. Journal of Environmental Psychology, 42, 116-122.
Poon, K.-T., Teng, F., Wong, W.-Y., \&t Chen, Z. (2016). When nature heals: Nature exposure moderates the relationship between ostracism and aggression. Journal of Environmental Psychology, 48, 159-168.

Russell, D. W. (1996). UCLA Loneliness Scale (Version 3): Reliability, validity, and factor structure. Journal of Personality Assessment, 66, 20-40.

Ryff, C. D., \& Keyes, C. L. M. (1995). The structure of psychological well-being revisited. Journal of Personality and Social Psychology, 69, 719-727.

Saroglou, V., Buxant, C., \&t Tilquin, J. (2008). Positive emotions as leading to religion and spirituality. The Journal of Positive Psychology, 3, 165-173.

Schultz, P. W. (2002). Inclusion with nature: The psychology of human-nature relations. In P. Schmuck \& W. P. Schultz (Eds.), Psychology of Sustainable Development (pp. 61-78). New York, NY: Springer.

Singer, P. (2011). The expanding circle: Ethics, evolution, and moral progress: Princeton, NJ: Princeton University Press.

Tam, K.-P. (2013). Concepts and measures related to connection to nature: Similarities and differences. Journal of Environmental Psychology, 34, 64-78.

Trigwell, J. L., Francis, A. J., \&t Bagot, K. L. (2014). Nature connectedness and eudaimonic well-being: Spirituality as a potential mediator. Ecopsychology, 6, 241-251.

Waytz, A., \& Epley, N. (2012). Social connection enables dehumanization. Journal of Experimental Social Psychology, 48, 70-76.

Wilson, E. O. (1984). Biophilia. Cambridge, MA: Harvard University Press.

Zelenski, J. M., \&t Nisbet, E. K. (2014). Happiness and feeling connected: The distinct role of nature relatedness. Environment and Behavior, 46, 3-23.

Address correspondence to:

Sam Moreton

School of Psychology

University of Sydney

Brennan MacCallum Building A18

Manning $R d$

Camperdown, NSW 2006

Australia

E-mail: smor6020@uni.sydney.edu.au

Received: July 8, 2018 Accepted: October, 282018 